\title{
Expressões da Educação Permanente na Atenção Primária à Saúde: uma revisão integrativa
}

\author{
Expressions of Permanent Education in Primary Health Care: an integrative review
}

Camila Ruszkovski Marques JOSINO*
https://orcid.org/o0oo-00o1-9789-6154

\section{Míriam Thais Guterres DIAS**}

https://orcid.org/o0oo-0002-3881-4961

Resumo: O artigo apresenta resultados de pesquisa sobre Educação Permanente em Saúde na Atenção Primária, no âmbito nacional. O objetivo geral foi o desenvolvimento de uma Revisão Integrativa nas produções científicas presentes nas bases de dados indexadas de pesquisas qualitativas sobre EPS na APS, para analisar a aplicação da sua metodologia na realidade brasileira. Seguindo os critérios de inclusão, totalizaram-se 20 estudos selecionados para análise, dos 2.340 artigos correspondentes aos descritores utilizados. Foi possível constatar o desconhecimento acerca da PNEPs e sobre sua metodologia.

Palavras-chave: Educação Permanente em Saúde; Educação Permanente; Educação Continuada; Atenção Primária à Saúde; Revisão Integrativa.

Abstract: The article presents the results of research on Permanent Education (PE) in Primary Health Care (PHC) at the national level. The objective was to develop an Integrative Review of the scientific works, within indexed databases, of qualitative research on PE in PHC, to enable an analysis of the application of its methodology in the Brazilian reality. Following the inclusion criteria, from the 2,340 articles corresponding to the descriptors used, 20 studies were selected for analysis. It was possible to verify a lack of knowledge about PE in PHC and its methodology.

Keywords: Permanent Education in Health; Permanent Education; Continuing Education; Health education; Primary Health Care; Integrative Review.

Submetido em: 10/7 2019. Revisado em: 14/11/2019. Aceito em: 9/2/2020.

\section{Introdução}

A Seguridade Social instituída no País se caracteriza como um sistema híbrido, pois a Previdência Social apresenta direitos derivados e dependentes do trabalho, da Saúde com direitos de caráter universal, e da Assistência Social para prover os mínimos sociais (BRASIL, 1988). Sua referência histórica é o modelo bismarckiano, na

\footnotetext{
${ }^{*}$ Enfermeira. Mestre em Política Social e Serviço Social. Unidade da Saúde da Família da Secretaria Municipal de Saúde de Porto Alegre. (SMSPA, Porto Alegre, Brasil). Av. João Pessoa, 325, Porto Alegre. E-mail: camilarm2010@gmail.com.

** Assistente social. Doutora em Serviço Social. Docente no Programa de Pós-Graduação em Política Social e Serviço Social, Universidade Federal do Rio Grande do Sul. (UFRGS, Porto Alegre, RS). Av. Paulo Gama, 110, Porto Alegre. E-mail: miriamtgdias@gmail.com.
}

(C) A(s) Autora(s)/O(s) Autor(es). 2019 Acesso Aberto Esta obra está licenciada sob os termos da Licença Creative Commons Atribuição 4.0 Internacional (https://creativecommons.org/licenses/by/4.o/deed.pt_BR), que permite copiar e redistribuir o material em qualquer suporte ou formato, bem como adaptar, transformar e criar a partir deste material para qualquer fim, mesmo que comercial. O licenciante não pode revogar estes direitos desde que você respeite os termos da licença. 
Alemanha, de 1883. Este sistema de seguro social possui características semelhantes a um seguro privado, pois é dependente de uma contribuição prévia de empregados e empregadores. Durante a Segunda Guerra Mundial, em 1942, na Inglaterra, o Plano de Beveridge estabelece um modelo em que o Estado é o responsável por assegurar os direitos sociais dos cidadãos. Este caráter igualitário, o plano oferece a garantia mínima de benefícios universal e independente de contribuição prévia, visto que o acesso a estes está relacionado às necessidades dos indivíduos (BOSCHETTI, 2003; GIOVANELLA; MENDONÇA, 2008).

Nesta mesma época, as políticas sociais surgem com o objetivo de corrigir as desigualdades originadas no mercado. O Estado é o responsável pela administração e o financiamento do sistema, destinando recursos do orçamento público para a sua manutenção. A Constituição Federal de 1988 incluiu a saúde como integrante da Seguridade Social para garantir, a todo cidadão, o acesso a esta necessidade básica (BRASIL, 1988). O Sistema Único de Saúde (SUS), instituído há quase 30 anos devido ao Movimento da Reforma Sanitária brasileira, por meio da Lei Orgânica da Saúde (Lei 8.080/1990), regula, no país, as ações e serviços de saúde como um direito fundamental do ser humano e dever do Estado em prover as condições necessárias (BRASIL, 1990).

A construção da saúde, como uma política social, envolve muitos aspectos, como os políticos, institucionais, econômicos, sociais, ideológicos, técnicos, culturais, dentre outros. Compondo um sistema de proteção social, enfrenta diversas formas de relação, seja entre gestores e atores políticos de unidades governamentais e empresas, indivíduos e grupos sociais, entre cidadãos e poderes políticos, consumidores ou entre provedores de bens de serviço; portanto, a saúde se encontra na relação entre Estado, sociedade e mercado. O cidadão financia a saúde com seus impostos e contribuições, assim como tem atitudes e preserva valores em relação ao seu cuidado construído socialmente; e o Estado define as normas e legislações, assim como cria serviços de atenção, desenvolve tecnologia e forma o recurso humano para trabalhar (GIOVANELLA; MENDONÇA, 2008).

A Política Nacional de Educação Permanente em Saúde (PNEPS) foi instituída pelo Ministério da Saúde, em 2004, visando transformar as práticas pedagógicas e de saúde, consistindo em uma estratégia SUS para a formação e o desenvolvimento de trabalhadores (BRASIL, 2004). Posteriormente, essa política foi reformulada em 2007, através da Portaria GM/MS no 1.996, para compor o Pacto pela Saúde, que estabeleceu as responsabilidades de cada esfera de governo, no que se refere à educação na saúde (BRASIL, 2009).

Como uma prática educativa pautada no trabalho, tem como prerrogativa a problematização da realidade, levando em consideração as determinações sociais da saúde e a transformação dos processos de trabalho, com vistas à ruptura de paradigmas hegemônicos centrados na racionalidade técnica e na saúde biomédica (BUSS; PELEGRINI-FILHO, 2007; CARVALHO; ALMEIDA; BEZERRA, 2016). A PNEPS objetiva a formação permanente dos trabalhadores da saúde, garantindo a correlação entre educação e resolutividade dos seus serviços (BRASIL, 2007). 
A categoria referente ao trabalho se faz presente nas políticas sociais existentes, por ser o exercício de uma atividade vital, responsável pela criação de bens materiais e simbólicos considerados, para a sociedade, necessários para a sua sobrevivência (OFFE, BERGER, 1991). Na área da saúde, é peculiar a diversidade de formas organizativas e de processos de trabalho, podendo ser, no modo de cooperação simples, presente nas clínicas de assistência médica com a primazia de uma divisão manufatureira. Isso ocorre, por exemplo, em unidades básicas de saúde, com menor predomínio de tecnologia; ou sob forma de maquinaria, a exemplo de hospitais e laboratórios de análises clínicas (ASSUNÇÃO, 2011).

A Educação Permanente em Saúde (EPS) é entendida como uma política, cuja missão principal é a de materializar o encontro entre educação e saúde, com o intuito de superar os problemas do cotidiano das equipes de saúde. Sendo assim, a articulação entre ensino, atenção, controle social e gestão e o conhecido quadrilátero da EPS possibilitam o alcance dos objetivos desta política (CECCIM; FEUERWERKER, 2004).

Considerando as orientações e prerrogativas da PNEPS a serem desenvolvidas nos serviços de saúde, foi elaborado o seguinte problema de pesquisa: Como vem sendo compreendida e desenvolvida a metodologia da Educação Permanente para a qualificação dos processos de trabalho nos serviços de Atenção Primária à Saúde (APS) brasileiros?

Em consequência desta problematização, o objetivo geral para este estudo é o de desenvolvimento de uma Revisão Integrativa nas produções científicas resultantes de pesquisas qualitativas sobre EPS, na APS, no âmbito nacional. Almeja, ainda, analisar a aplicação da sua metodologia na realidade brasileira, visando contribuir no processo de elaboração e sistematização de políticas no âmbito da saúde pública.

\section{Método}

Esta pesquisa foi proveniente de um programa de mestrado, do tipo exploratória, da modalidade revisão integrativa da literatura científica. As categorias utilizadas são a Atenção Primária à Saúde, Educação Permanente em Saúde e Trabalho. A coleta de dados da pesquisa realizou-se do segundo semestre de 2017 até o primeiro semestre de 2018.

A Revisão Integrativa é um tipo de revisão bibliográfica que permite sintetizar estudos já publicados, com a sumarização e a elaboração de conclusões acerca do assunto. Esta revisão pretende determinar o conhecimento atual sobre certa temática e contribuir para o desenvolvimento de políticas, protocolos, procedimentos e pensamento crítico, exigidos no cotidiano de trabalho dos profissionais (SOUZA; SILVA; CARVALHO, 2010).

A Revisão Integrativa é um método de pesquisa consolidado e que possui como principal característica a incorporação de evidências na prática clínica (MENDES; SILVEIRA; GALVÃO, 2008). Seu método consiste na definição do objetivo, formulação dos questionamentos a serem respondidos ou das hipóteses a serem testadas, bem

Argum., Vitória, v. 12, n. 1, p. 207-221, jan./abr. 2020. | ISSN 2176-9575 
como na realização da busca para identificação do maior número de pesquisas primárias relevantes, considerando os critérios de inclusão e exclusão, previamente estabelecidos. As suas seis etapas foram executadas: identificação do tema e seleção da questão de pesquisa; definição dos critérios de inclusão e exclusão do estudo; seleção e categorização dos estudos; análise e interpretação dos resultados; e por fim, apresentada a síntese da revisão (MENDES; SILVEIRA; GALVÃO, 2008).

Os critérios de inclusão foram: artigos científicos originais e completos de pesquisas qualitativas indexados em bases de dados, que responderam à questão norteadora, de 2004 a 2018, período posterior à publicação da PNEPS (2004), nos idiomas português, inglês e espanhol, disponíveis na sua íntegra e de forma gratuita e online. Foram excluídos deste estudo as teses de doutorado; dissertações de mestrado; monografias; documentos e anais de eventos.

As bases de dados eletrônicos utilizadas foram o Sistema da Literatura LatinoAmericana e do Caribe, em Ciências da Saúde (LILACS), Medical Literature Analysis and Retrieval System Online (MEDLINE), no Scientific Eletronic Library Online (SciELO) e no Índice Bibliográfico Espanhol das Ciências da Saúde (IBECS). A busca em publicações internacionais objetivou encontrar pesquisas sobre estudos brasileiros referentes ao tema. Foram encontrados um total de 2.340 artigos, na busca pelos descritores separados quanto à origem das línguas portuguesa, inglesa e espanhola, visto que há variabilidade na tradução entre os idiomas.

Posteriormente, foi utilizada a análise de conteúdo (MORAES, 1999) e o software NVivo Plus 11, com intuito de facilitar a estocagem, o gerenciamento e a recuperação de dados (COFFEY; HOLBROOK; ATKINSON, 1996). O projeto foi submetido à apreciação da Comissão de Pesquisa do Instituto de Psicologia, da Universidade Federal do Rio Grande do Sul, e foi aprovado em 23/03/2018, com o número 34.609.

\section{Resultados}

Os artigos que compõem este estudo foram publicados no período de 2010 a 2017, evidenciando que a discussão da EPS, na relação com a APS, não se iniciou logo após a Portaria de 2004, ou a sua reformulação em 2007. A região Nordeste tem mais artigos publicados, num total de oito, já a região Sul apresentou seis artigos, a Sudeste possui cinco artigos, e a Centro-Oeste apenas um, que contemplou esta temática.

A análise dos dados considerou as categorias analíticas estabelecidas, que, aplicadas nos conteúdos sobre educação permanente recorrentes nos artigos selecionados, gerou as categorias finais deste estudo. Estas categorias foram: o conceito de EPS na APS, a formação profissional, o SUS e a política pública, e, os dispositivos para a prática de EPS.

O conceito de EPS foi uma categoria presente quase que na totalidade dos artigos analisados, visto que a nomenclatura ainda permite que equívocos sejam cometidos e termos como educação permanente e educação continuada sejam utilizados como sinônimos. As subcategorias encontradas foram: o conceito de EPS; as atividades 
realizadas como EPS; o planejamento, a avaliação e a sistematização do processo de EPS.

Frente aos resultados encontrados neste estudo, pode-se, ainda, observar o desconhecimento dos conceitos de EPS e de Educação Continuada (EC), pois, em 10 dos 20 artigos analisados, existe uma confusão conceitual entre EPS e EC. O equívoco está presente também entre os termos Educação em Saúde (ES) e Educação Permanente (EP), pois são utilizados como sinônimos, quando a ES pode ser caracterizada como um espaço de trocas de conhecimento, de práticas relacionadas à cultura dos indivíduos, de forma convergente aos pressupostos da promoção da saúde (BARTH et al., 2014).

A subcategoria intitulada de Atividades realizadas de EPS evidenciou termos como: cursos, capacitações, treinamentos, atualizações reuniões, palestras, aperfeiçoamento, reciclagem, dentre outras. Surgem como sinônimos para a atualização do conhecimento dos profissionais, acontecendo, em sua maioria, de maneira pontual, fragmentada e direcionada para as categorias profissionais (CORIOLANO et al., 2012; LIMA; ALBUQUERQUE; WENCESLAW, 2014; RICARDI; SOUSA, 2015).

A compreensão do planejamento, da avaliação e do monitoramento dos processos educativos para tomada de decisões foi notável nos estudos com vistas a propor futuras alterações e orientações do processo de trabalho das equipes (LINO et al., 2009; BALBINO et al., 2010; TESSER et al., 2011; CORIOLANO et al., 2012; LIMA; ALBUQUERQUE; WENCESLAU, 2014; RICARDI, SOUSA; 2015; MISHIMA et al. 2015; PERES, SILVA, BARBA; 2016; SILVA et al. 2016; BOMFIM et al. 2017; SILVA et al., 2017). $\mathrm{O}$ que se observa é uma avaliação quantitativa das atividades desenvolvidas (número de horas, participantes e dias trabalhados) sem relação com o processo de trabalho, e sem contribuição com o processo de educação permanente (SILVA et al., 2016).

Artigos apontam a presença do modelo biomédico na área da saúde, com a sua formação técnico-científica centrada no modelo tradicional de transmissão de conhecimento (LINO et al., 2009; BALBINO et al., 2010; COSTA et al., 2010; DUARTE et al., 2011; TESSER et al., 2011; BARBOSA; FERREIRA; BARBOSA, 2012; CORIOLANO et al., 2012; BARTH et al., 2014; LIMA; ALBUQUERQUE; WENCESLAU, 2014; RICARDI; SOUSA, 2015; ANDRADE et al., 2016; CARVALHO; ALMEIDA; BEZERRA, 2016; PERES; SILVA; DELLA BARBA, 2016; SILVA et al., 2016; SILVA et al., 2017; BISPO JÚNIOR, MOREIRA, 2017; SENA et al., 2017; BOMFIM et al., 2017). No entanto, a educação é constituída por um processo de construção coletiva do saber entre os trabalhadores, considerando o contexto de trabalho. A educação, para Paulo Freire, é comunicativa e emancipatória, diferentemente do proposto na educação tradicional, com o predomínio da transferência de conteúdo, não permitindo que a criatividade e a participação dos envolvidos ocorra (FREIRE, 1980).

Em relação aos gestores, foram identificados, em 11 estudos, que o profissional da gestão, seja Municipal, Estadual ou Federal, desconhece a EPS ou a confunde com outros conceitos, como o EC ou ES (LINO et al., 2009; TESSER et al., 2011; RICARDI, SOUSA, 2015; CARVALHO; ALMEIDA; BEZERRA, 2016; PERES; SILVA; DELLA BARBA,

Argum., Vitória, v. 12, n. 1, p. 207-221, jan./abr. 2020. | ISSN 2176-9575 
2016; LIMA; ALBUQUERQUE; WENCESLAU, 2014; BISPO JÚNIOR, MOREIRA, 2017; BOMFIM et al., 2017; SILVA et al., 2017). Estes estudos evidenciaram que os gestores não valorizam esta importante ferramenta para o aperfeiçoamento das equipes, revitalização do conhecimento, geração de mudanças e qualificação da gestão e da atenção. $\mathrm{O}$ estímulo constatado se restringe à participação dos profissionais em cursos e treinamentos que visam ao aprimoramento tecnicista individual e focam em categorias profissionais (SILVA et al., 2017; MISHIMA et al., 2015; LIMA; ALBUQUERQUE; WENCESLAU, 2014; LINO et al., 2009).

Os gestores dos serviços públicos, de uma maneira geral, ocupam-se, prioritariamente, com questões administrativas, como áreas física e tecnológica, deixando em segundo plano as ações relacionadas à formação dos trabalhadores das instituições e a assistência prestada por eles (PERES; SILVA; DELLA BARBA, 2016). Sendo assim, o investimento no conhecimento dos profissionais ocorre através da denominada educação bancária ou tradicional. Nesta é observada apenas a transmissão verticalizada do conhecimento, e o indivíduo a que se destina tal atividade, se limita apenas a apreender o que lhe é ofertado e após reproduzir no seu cotidiano de trabalho (FREIRE, 1980). Portanto, é preciso repensar a formação em saúde no Brasil, a qual precisa ser uma prioridade para o bem-estar da sociedade. Através da PNEPS, é possível começar a propor esta mudança de paradigma, e em um processo contínuo, se reestruturar o sistema de saúde brasileiro (CARVALHO; ALMEIDA; BEZERRA, 2016).

O profissional da área de enfermagem foi um destaque nos processos de educação permanente por ser o responsável pela maioria dos artigos publicados, num total de dezesseis. Inúmeras são as justificativas para a presença deste profissional, como a sua formação com enfoque gerencial nas atividades com os ACS e a equipe de enfermagem (técnicos e auxiliares de enfermagem) bem como, com os usuários na APS, assumindo a liderança de facilitador da EPS nas unidades de saúde, na APS. As publicações de outros profissionais foram: por médico (nove), agente comunitário de saúde (oito), técnico e auxiliar de enfermagem (seis), assistente social (cinco), odontólogo (cinco) e psicólogo (quatro), todos integrantes da APS.

Referente à categoria analítica, intitulada SUS e política pública, constatou-se a finalidade da EPS de possibilitar a reflexão e a intervenção sobre o processo de trabalho, objetivando superá-la, modificá-la e transformá-la em uma nova situação. Sendo assim, a EPS busca desenvolver práticas educativas baseadas na problematização do cotidiano.

O financiamento foi abordado em três artigos considerados significativos (RICARDI; SOUSA, 2015; TESSER et al., 2011; PERES; SILVA; DELLA BARBA, 2016), por tratarem de uma subcategoria deste estudo. Desde os anos 1990, começam as transferências de recursos entre os entes federados para o financiamento de ações e serviços em saúde. O Pacto de Gestão, em 2006, criou seis Blocos para a transferência fundo a fundo, cinco para as despesas de custeio da atenção à saúde e um para o investimento na Rede de Serviços de Saúde. O financiamento da EPS, por sua vez, ficava no Bloco de custeio da Gestão do SUS, o que foi alterado com a Portaria no 3.992, de 28/12/2017, quando estabeleceu um bloco de custeio e um de investimento. 
A última categoria analisada foi referente aos dispositivos utilizados para a prática de EPS. Nos artigos de Costa et al. (2010); Duarte et al. (2011); Silva et al. (2017); Lima, Albuquerque e Wenceslau (2014); Ricardi e Sousa (2015); Andrade et al. (2016); Silva et al. (2017); Bomfim et al. (2017) e Bispo Júnior e Moreira (2017) foram elencadas as reuniões que ocorrem por microrregionais de saúde, o apoio matricial (AM), o apoio institucional (AI), o uso de projetos terapêuticos singulares (PTS) e da consulta compartilhada, onde se discutem casos clínicos.

O Apoio Matricial consiste em um modelo de cuidados colaborativos no SUS, com vistas ao cuidado integral à saúde (ATHIÉ; FORTES; DELGADO, 2013), requerendo a troca de saberes entre as equipes e profissionais, com vistas a novas ações para debelar os problemas de saúde, construindo espaços de comunicação ativa e compartilhamento de conhecimento entre a equipe de assistência e a de matriciamento. Esta tem a responsabilidade de conduzir o caso estabelecendo o vínculo e garantindo o cuidado longitudinal (CAMPOS; DOMITTI, 2007; OLIVEIRA, 2008).

O Apoio Institucional se realiza por uma equipe composta por diversos profissionais de saúde que atuam apoiando os gestores e as equipes assistenciais, com uso em especial de recursos pedagógicos (MOURA et al., 2007). Nesta definição fica evidente a diferença entre AM e AI, pois o primeiro vem para reorganizar a lógica das relações entre os profissionais generalistas e os especialistas, democratizando as relações de poder das equipes de saúde na direção da integralidade do cuidado. Já o AI surge como um método e uma estratégia de gestão da atenção à saúde.

O PTS também foi considerado um dispositivo com potencial para desenvolver a prática de EPS, enquanto um movimento de coprodução e cogestão do processo terapêutico dos usuários ou grupos que se encontram em vulnerabilidade e necessitam que seja construído de maneira coletiva um plano de cuidados, envolvendo o profissional, a equipe, o usuário e a família, incorporando a noção interdisciplinar no projeto terapêutico (LIMA; ALBUQUERQUE; WENCESLAU, 2014).

\section{Discussão}

O termo educação permanente apareceu, pela primeira vez, na França, em 1955, e, ao final da década de 1960, passou a ser difundido pela Organização das Nações Unidas para a Educação, a Ciência e a Cultura (UNESCO). É fundamentado na teoria do capital humano, destacando a importância da qualificação humana como um meio para a produtividade econômica e o desenvolvimento dos países. A EPS surge em 1980, como uma estratégia do Programa de Desenvolvimento Humano da Organização Pan Americana de Saúde (OPAS), quando faz a diferenciação dos termos Educação permanente e Educação continuada, a última relacionada à educação formal de transmissão de conhecimento (LEMOS, 2016).

A intenção da OPAS, segundo Lemos (2016), foi elaborar um novo referencial pedagógico que envolvesse mais o trabalhador no processo produtivo da saúde, com vistas a superar a fragmentação, a alienação e a desumanização do trabalho. Houve a

Argum., Vitória, v. 12, n. 1, p. 207-221, jan./abr. 2020. | ISSN 2176-9575 
pretensão de superar a rigidez na repetição de tarefas desprovidas de sentidos que imperava, características do taylorismo e fordismo, e dar espaço ao novo modo de reestruturação produtiva do capital no mundo do trabalho da saúde, o toyotismo, criando uma lógica integrativa e flexível na organização do trabalho.

A EPS oferece grandes e valiosos elementos para uma avaliação técnica, pedagógica, filosófica e política do processo formativo e de aperfeiçoamento constante dos profissionais da saúde, frente aos desafios apresentados no cotidiano de trabalho. Traz como premissa a concepção de educação enquanto transformação, em que a aprendizagem significativa se faz presente, e valoriza o cotidiano enquanto fonte do conhecimento, devendo garantir a articulação da atenção com a gestão e o controle social (CECCIM; FEUERWERKER, 2004; PEDUZZI, 2009).

Observada a diferença da EC e da EPS, vê-se que a primeira está pautada na concepção de educação enquanto transmissão de conhecimento, valorizando a ciência como principal fonte de conhecimento. Já a segunda, frente aos desafios impostos pela APS, caminha para a construção de valores, métodos e práticas democratizantes de gestão do trabalho no SUS, com vistas à qualificação do trabalho. Ademais, pauta-se na concepção pedagógica e emancipatória para promover processos educativos, visando a transformação das práticas de saúde e de educação (CECCIM, 2005).

Porém, a falta de clareza entre os conceitos de EPS, EC e ES produz um obstáculo para a PNEPS se efetivar na APS, pois muitos são os conceitos utilizados, assim como diversas são as ações na prática, por isso a sua avaliação e monitoramento não são vistos como prioridade. A compreensão que prevaleceu nos estudos foi de que a EPS faz parte de um modelo formativo e deve se desenvolver através de cursos, treinamentos e capacitações com profissionais especialistas, dentro ou fora dos serviços de saúde. Estas modalidades de qualificação são relevantes para a atualização das questões técnicas do trabalho em saúde, pois a tecnologia e o cuidado são necessários. No entanto, caracterizar ou nomear a metodologia de educação permanente como cursos pontuais são um equívoco e desconsideram as premissas da PNEPS.

A presença das instituições formadoras nos processos de EPS ainda é frágil, assim como sua ausência no processo formativo durante a graduação. Os artigos que apresentaram a universidade incorporada aos processos formativos das equipes de saúde referem-na como uma prática desarticulada dos processos de trabalho e uma alternativa de atualização de determinadas categorias profissionais (LINO et al., 2009; BALBINO et al., 2010; COSTA et al., 2010; DUARTE et al., 2011; CORIOLANO et al., 2012; BARTH et al., 2014; LIMA; ALBUQUERQUE; WENCESLAU, 2014; RICARDI, SOUSA, 2015; MISHIMA et al., 2015; SILVA et al., 2016; SENA et al., 2017; BISPO JÚNIOR, MOREIRA, 2017; BOMFIM et al., 2017).

Ficou evidente, no estudo, que a existência de uma política pública não garante a sua efetiva presença nos cotidianos de trabalho. Muitos fatores a explicam, mas a sua compreensão e movimentos de reivindicação de trabalhadores, usuários e gestores são primordiais para sua efetivação nos ambientes de saúde do país. Igualmente, o 
planejamento, o monitoramento e a avaliação da execução de uma política pública são de vital importância para sua efetivação no cotidiano dos serviços.

Para os trabalhadores se apropriarem e assumirem o compromisso com a EPS, o incentivo deve iniciar ainda na academia, permitindo a problematização de questões que serão experenciadas na prática profissional, ao término da graduação. O que está presente, no momento, é a técnica de transmissão do conhecimento, sem relação entre teoria e prática, com o modelo biomédico hegemônico, que influencia a formação na área da saúde, gerando a tecnicidade e a aplicação da clínica tradicional (CARVALHO; ALMEIDA; BEZERRA, 2016). Contudo, a formação na área da saúde tem real importância na construção do SUS e, é neste cenário, que se preconiza a EPS, pois as transformações sociais e educacionais têm repercussões nos modos de produzir, nos diferentes campos do saber e de produção de bens de serviços (RICARDI, SOUSA, 2015; SENA et al., 2017).

A interação entre ensino, pesquisa e serviço se faz essencial, principalmente no que concerne aos processos de EPS, pois é incorporada ao contexto de trabalho das equipes. Isso faz com que o SUS seja mais que um campo de estágio ou de aprendizagem, mas uma política pública que requisita interlocução das instituições formadoras para a implementação de projetos políticos-pedagógicos na formação profissional (CECCIM, 2005; RICARDI, SOUSA, 2015).

Frente a isso, evidencia-se o potencial do enfermeiro no desenvolvimento e condução de atividades de EPS, com os ACS e os demais integrantes da equipe de saúde. Assim, deve estar fundamentada e inserida no contexto de trabalho, contribuindo para o compartilhamento de experiências e saberes, de forma ascendente e descentralizada, partindo das necessidades locais dos territórios.

Entre os fatores considerados dificultadores, a rotatividade de recursos humanos foi uma das mais presentes, pois a falta de profissionais nos serviços tornou-se um obstáculo para a qualificação profissional, e dificultou o alcance dos princípios e diretrizes do SUS, como o vínculo dos usuários com o trabalhador e o cuidado longitudinal (LIMA; ALBUQUERQUE; WENCESLAU, 2014). Esta realidade está diretamente relacionada à fragilidade do financiamento das políticas públicas, em especial a saúde, agravada com a promulgação da Emenda Constitucional no 95 (BRASIL, 2016), limitando por 20 anos os gastos com serviços públicos, e tendo como consequência a precarização das condições de trabalho e a atenção à saúde.

O desconhecimento da EPS por parte dos sujeitos dificulta a implementação da PNEPS, contribuindo na falta de esforços para sua efetiva presença nos serviços de saúde. Isso permite que as ações sigam se realizando de modo verticalizado e sem diálogo entre os gestores e trabalhadores sobre experiências de EPS. Outro desafio para a efetivação da PNEPS é a inexistência de um profissional responsável nos municípios. Para Peres, Silva e Della Barba (2016), o cargo de articulador como elo entre a gestão e os profissionais deve ser efetivado e valorizado, com atribuições definidas para desenvolvimento de atividades de EPS. 
A dificuldade apresentada pelos gestores na APS relacionou-se à apropriação conceitual da EPS, devido a pouca aproximação entre as instituições formadoras e os serviços de saúde. Estes estão associados a não exigência de quesitos referentes à compreensão de Políticas Públicas para a ocupação de cargos na gestão municipal. Constata-se, também, que as ações dos gestores se direcionam para as ações que tenham visibilidade à população, deixando o investimento na educação dos trabalhadores para um segundo plano. Isso porque, a formação em serviço deveria ser uma prioridade nas pautas de gestão, produzindo qualidade dos serviços e da assistência oferecida à população.

Na categoria analítica dos dispositivos para intervenção no contexto dos serviços, foram encontrados: o apoio matricial, o apoio institucional, o projeto terapêutico singular, a interconsulta, a consulta conjunta, grupos, oficinas, e os Núcleos de Apoio à Saúde da Família enquanto estratégias para sua implementação. Para Oliveira (2008), o AM é capaz de alterar as condições de saúde pela construção de espaços de comunicação ativa e compartilhamento de conhecimento entre a equipe de referência e a de apoiadores. Esta tem a responsabilidade na condução de um caso individual, familiar ou comunitário pela construção de vínculo, garantindo o cuidado longitudinal, como preconizado pelas equipes de saúde da família na APS (CAMPOS; DOMITTI, 2007).

Fica perceptível que as políticas devem se relacionar para que os princípios do SUS sejam efetivados. Dessa maneira, através de métodos diferenciados, será possível experienciar e garantir que sejam, definitivamente, executadas junto à população assistida.

\section{Conclusão}

Os resultados deste estudo evidenciaram que a EPS tem como propósito contribuir para a transformação das práticas pedagógicas e de saúde, enquanto estratégia do SUS para formação em serviço de trabalhadores. Destaca-se, ainda, a constatação de ser necessário um debate sobre a EPS nos ambientes de trabalho e entre todos os sujeitos envolvidos na atenção à saúde.

Tal proposta enfrenta certa dificuldade de se expressar no neoliberalismo, em um país que tem um sistema de saúde universal sob risco de intensificação de retrocessos. A EPS objetiva a reflexão e a problematização dos processos de trabalho, com vistas a mudanças em certos padrões de relação para com a população usuária da política pública de saúde.

O fortalecimento das políticas públicas para a formação e qualificação dos trabalhadores da saúde é uma exigência frente ao que foi possível verificar neste estudo. As mesmas objetivam que os profissionais assumam uma postura crítica e reflexiva em relação aos processos educativos. Almeja-se exercê-las de forma efetiva nos seus contextos de trabalho, uma vez que a EPS é essencial para que possam repensar suas ações e, assim, buscar, através da problematização, a integralidade, a resolutividade e a humanização da atenção em saúde. 
A finalidade da EPS, ainda que pouco discutida no cotidiano das equipes de saúde de uma maneira geral no Brasil, nada mais é do que uma estratégia de qualificação da atenção em saúde. Sendo assim, as especificidades regionais e a superação das suas desigualdades, as necessidades de formação e o desenvolvimento para o trabalho em saúde são seus objetivos. $\mathrm{O}$ uso de métodos, como o da aprendizagem significativa, possibilita a reflexão diária dos processos de trabalho, o que facilita a busca da formação pelos profissionais do SUS. Sendo assim, a EPS deve ser compreendida como um instrumento do e no trabalho das equipes de saúde da APS, uma vez que consiste na colaboração para a aquisição de capacidades de ser coautor nos processos de modificações e de reestruturações dos serviços de saúde.

Finaliza-se, então, com uma proposta de que a PNEPS seja uma prioridade nas agendas dos gestores nos municípios brasileiros. Além disso, sugere-se que esta Política possa ter o seu devido reconhecimento e, assim, consequente utilização no cotidiano das equipes de saúde. Através dos dispositivos, como o exemplo do Apoio Matricial e do Apoio Institucional, pode-se começar a pensar em momentos de reflexão e problematização dos processos de trabalho e de questões peculiares de cada território do país.

\section{Referências}

ANDRADE, R. S.; CALDAS, L. B. S. do N.; FALCÃO, M. L. P.; GÓES, P. S. A. Processo de trabalho em unidades de saúde da família e a educação permanente. Trabalho, Educação e Saúde, Rio de Janeiro, v. 14, p. 505-521, 2016. Disponível em: http://www.scielo.br/pdf/tes/v14n2/1678-1007-tes-1981-7746-sipoo108.pdf . Acesso em: 10 set. 2017.

ASSUNÇÃO, A. A. Trabalhar na saúde: experiências cotidianas e desafios para a gestão do trabalho e do emprego. Rio de Janeiro: Fiocruz, 2011.

ATHIÉ, K.; FORTES, S.; DELGADO, P.G.G. Matriciamento em saúde mental na Atenção Primária: uma revisão crítica (2000-2010). Revista Brasileira de Medicina de Família e Comunidade, Rio de Janeiro, v. 8, n. 26, p. 64-74, 2013. Disponível em: https://rbmfc.emnuvens.com.br/rbmfc/article/view/536/530. Acesso em: 10 set. 2017.

BALBINO, A. C. et al. Educação permanente com os auxiliares de enfermagem da Estratégia Saúde da Família em Sobral, Ceará. Trabalho, Educação e Saúde, Rio de Janeiro, v. 8, p. 249-266, jul. /out. 2010.

BARBOSA, V. B. A.; FERREIRA, M. L. S. M.; BARBOSA, P. M. K. Educação permanente em saúde: uma estratégia para a formação dos agentes comunitários de saúde. Revista Gaúcha de Enfermagem, Porto Alegre, v. 33, p. 56-63, 2012.

BARTH, P.O. et al. Educação permanente em saúde: concepções e práticas de enfermeiros de unidades básicas de saúde. Revista Eletrônica de Enfermagem, Goiânia, v. 16, p. 6o4-11, 2014. Disponível em:

https://www.revistas.ufg.br/fen/article/view/22020. Acesso em: 10 set. 2017.

Argum., Vitória, v. 12, n. 1, p. 207-221, jan./abr. 2020. | ISSN 2176-9575 
BISPO JÚNIOR, J. P.; MOREIRA, D.C. Educação permanente e apoio matricial: formação, vivências e práticas dos profissionais dos Núcleos de Apoio à Saúde da Família e das equipes apoiadas. Caderno de Saúde Pública, Rio de Janeiro, v. 33, n. 9, 2017.

BOMFIM, E. S. et al. Educação permanente no cotidiano das equipes de saúde da família: utopia, intenção ou realidade? Revista da Escola de Enfermagem Alfredo Pinto, Rio de Janeiro, v. 9, p. 526-535, 2017.

BOSCHETTI, I. Assistência Social no Brasil: um direito entre originalidade e conservadorismo. Brasília: GESST/SER/UnB, 2003.

BRASIL. Ministério da Saúde. Portaria GM/MS no 198, de 13 de fevereiro de 2004. Institui a Política Nacional de Educação Permanente em Saúde como estratégia do Sistema Único de Saúde. Diário [da] República Federativa do Brasil, Brasília (DF), fev. 2004. Seção 1. Disponível em: https://www.nescon.medicina.ufmg.br/biblioteca/imagem/1832.pdf $>$. Acesso em: 5 set. 2016.

BRASIL. Presidência da República. Emenda Constitucional no 95. Altera o Ato das Disposições Constitucionais Transitórias, para incluir o Novo Regime Fiscal e dá outras providências. Brasília (DF), 2016. Disponível em:

https://www2.camara.leg.br/legin/fed/emecon/2016/emendaconstitucional-95-15dezembro-2016-784029-publicacaooriginal-151558-pl.html. Acesso em: 2 nov. 2019.

BRASIL. Ministério da Saúde. Política Nacional de Educação Permanente em Saúde. v. 9. Brasília (DF), 2009. (Série Pactos pela Saúde 2006).

BRASIL. Ministério da Saúde. Portaria GM//MS no 1996, de 20 de agosto de 2007. Dispõe sobre as diretrizes para a implementação da Política Nacional de Educação Permanente em Saúde e dá outras providências. Diário [da] República Federativa do Brasil, Brasília (DF), 20 ago. 2007. Disponível em: http://bvsms.saude.gov.br/bvs/saudelegis/gm/2007/prt19g6 2008 2007.html. Acesso em: 5 set. 2017.

BRASIL. Presidência da República. Lei no 8.080, de 19 de setembro de 1990. Dispõe sobre as condições para a promoção, proteção e recuperação da saúde, a organização e o funcionamento dos serviços correspondentes e dá outras providências. Brasília (DF), 1990.

BRASIL. [Constituição de 1988]. Constituição da República federativa do Brasil de 1988. Brasília (DF): Senado Federal; Centro Gráfico, 1988.

BUSS, P. M.; PELLEGRINI-FILHO, A. A saúde e seus determinantes sociais. Physis, Rio de Janeiro, v. 17, n. 1, p. 77-93, 2007. 
CAMPOS, G. W. S.; DOMITTI, A. C. Apoio matricial e equipe de referência: uma metodologia para gestão do trabalho interdisciplinar em saúde. Trabalho, Educação e Saúde, Rio de Janeiro, v. 23, p. 399-407, 2007.

CARVALHO, T. G. S.; ALMEIDA, A. M. B. de; BEZERRA, M. I. C. Percepção dos profissionais de saúde da atenção primária sobre educação permanente em saúde. Revista Sanare, Sobral, v. 15, p. 94-103, 2016.

CECCIM, R. B. Educação permanente em saúde: descentralização e disseminação de capacidade pedagógica na saúde. Ciência \& Saúde Coletiva, Rio de Janeiro, v. 1o, n. 4, p. $975-86.3,2005$.

CECCIM, R. B.; FEUERWERKER, L. C. M. O quadrilátero da formação para a área da saúde: ensino, gestão, atenção e controle social. Physis, Rio de Janeiro, v. 14 n. 1, p. 4165, 2004 .

COFFEY, A.; HOLBROOK, B.; ATKINSON, P. Qualitative data analysis: technologies and representations. Sociological Research Online, v. 1, n. 1, 1996. Disponível em: https://journals.sagepub.com/doi/10.5153/sro.1. Acesso em: 23 mar. 2018.

CORIOLANO, M. W. L. et al. Educação permanente com agentes comunitários de saúde: uma proposta de cuidado com crianças asmáticas. Trabalho, Educação e Saúde, Rio de Janeiro, v. 10, n. 1, p. 37-59, 2012.

COSTA, V. Z. et al. Educação permanente no Programa de Saúde da Família: um estudo qualitativo. Revista Investimento, Educação em Enfermagem, São Paulo, v. 28, 2010.

DUARTE, S. J. H. et al. A educação permanente como possibilidade no diagnóstico precoce da tuberculose. Arquivos Catarinense de Medicina, Florianopólis, v. 40, n. 1, 2011.

FREIRE, P. Conscientização: teoria e prática da libertação, uma introdução ao pensamento de Paulo Freire. São Paulo: Moraes, 1980.

GIOVANELLA, L; MENDONÇA, M. H. M. Atenção primária à saúde. In: GIOVANELLA, L. et al. (Org). Políticas e sistema de saúde no Brasil. Rio de Janeiro: Fiocruz, 2008.

LEMOS, C. L. M. Educação permanente em saúde no Brasil: educação ou gerenciamento permanente? Ciência \& Saúde Coletiva, Rio de Janeiro, v. 21, n. 3, p. 913-922, 2016.

LIMA, S. A.V.; ALBUQUERQUE, P. C.; WENCESLAU, L. D. Educação permanente em saúde segundo os profissionais da gestão de Recife, Pernambuco. Trabalho, Educação e Saúde, Rio de Janeiro, v. 12, p. 425-441, 2014. 
LINO, M. M. et al. Educação permanente dos serviços públicos de saúde de Florianópolis, Santa Catarina. Trabalho, Educação e Saúde, Rio de Janeiro, v. 7, p. 115-136, 2009.

MENDES, K. D. S.; SILVEIRA, R. C. C. P., GALVÃO, C. M. Revisão Integrativa: Método de Pesquisa para a incorporação de evidências na saúde e na enfermagem. Texto Contexto Enfermagem, Florianópolis, v. 17, n. 4, p. 758-64, out./dez. 2008.

MISHIMA, S. M. et al. Perspectiva dos gestores de uma região do estado de São Paulo sobre educação permanente em saúde. Revista da Escola de Enfermagem da USP, São Paulo, v. 49, p. 665-673, 2015.

MORAES, R. Análise de conteúdo. Revista Educação, Porto Alegre, v. 22, n. 37, p. 732, 1999.

MOURA, A. H. et al. Análise do trabalho institucional nas equipes dos distritos sanitários e no hospital Mário Gatti, Campinas. In: CAMPOS, G. W. S. Saúde Paideia, São Paulo, v. 3, p. 167-185, 2007.

OFFE, C.; BERGER, J. Crescimento e racionalização do setor de serviços. In: OFFE, C. (org.) Trabalho e Sociedade: problemas estruturais e perspectivas para o futuro da sociedade de trabalho. Rio de Janeiro: Tempo Brasileiro, 1991.

OLIVEIRA, G. N. Apoio matricial como tecnologia de gestão e articulação em rede. In: CAMPOS, G. W. S.; GUERRERO, A. V. P. (Org.). Manual de práticas da atenção básica: saúde ampliada e compartilhada. São Paulo: Hucitec, p. 273-282, 2008.

PEDUZZI, M. Atividades educativas de trabalhadores na atenção primária: concepções de educação permanente e de educação continuada em saúde presentes no cotidiano de Unidades Básicas de Saúde em São Paulo. Interface Comunicação, Saúde, Educação, v. 13, n. 30, p. 121-134, 2009.

PERES, C.; SILVA, R. F. da; DELLA BARBA, P. C. S. Desafios e potencialidades do processo de educação permanente em saúde. Trabalho, Educação e Saúde, Rio de Janeiro, v. 14, p. 783-801, 2016.

RICARDI, L. M.; SOUSA, M. F. de. Educação permanente em alimentação e nutrição na Estratégia de Saúde da Família: encontros e desencontros em municípios brasileiros de grande porte. Ciência \& Saúde Coletiva, Rio de Janeiro, v. 20, p. 209-218, 2015.

SENA, R. R. et al. Educação permanente nos serviços de saúde: atividades educativas desenvolvidas no estado de Minas Gerais, Brasil. Revista Gaúcha de Enfermagem, Porto Alegre, v. 38, 2017.

SILVA, L. A. A. et al. Educação permanente em saúde na atenção básica: percepções dos gestores municipais de saúde. Revista Gaúcha de Enfermagem, Porto Alegre, v. 38, 2017. 
SILVA, L. A. A. et al. Avaliação da educação permanente no processo de trabalho em saúde. Trabalho, Educação e Saúde, Rio de Janeiro, v. 14, p. 765-781, 2016.

SOUZA, M. T.; SILVA, M. D.; CARVALHO, R. Revisão Integrativa: o que é e como fazer? Revista Einstein, São Paulo, v. 8, n. 1, 2010.

TESSER, C. D. et al. Estratégia saúde da família e análise da realidade social: subsídios para políticas de promoção da saúde e educação permanente. Ciência \& Saúde

Coletiva, Rio de Janeiro, v. 16, p. 4295-4306, 2011.

Camila Ruszkovski Marques JOSINO. Participou na concepção, delineamento e redação do artigo. Formada pela Universidade Federal do Rio Grande do Sul (UFRGS) em Enfermagem, especialista em Educação Permanente em Saúde pela UFRGS, Residência em Saúde da Família e Comunidade pelo Grupo Hospitalar Conceição (GHC) e Mestre em Política Social e Serviço Social da UFRGS.

Míriam Thais Guterres DIAS. Participou na concepção, na revisão crítica e na aprovação da versão a ser publicada.

Formada pela Pontifícia Universidade Católica do Rio Grande do Sul (PUCRS) em Serviço Social, especialista em Supervisão em Serviço Social pela PUCRS, em Saúde Mental Coletiva pela Universidade Federal de Santa Maria, e em Gestão de Redes de Atenção à Saúde pela ENSP/FIOCRUZ. Mestre e Doutora em Serviço Social pela PUCRS. Docente da graduação e mestrado em política Social e Serviço Social da UFRGS. Pesquisadora produtividade CNPq. Integrante do Comitê de Ética do Hospital de Clínicas de Porto Alegre.

Argum., Vitória, v. 12, n. 1, p. 207-221, jan./abr. 2020. | ISSN 2176-9575 